\title{
Disturbances in the Biosynthesis or Signalling of Brassinosteroids That Are Caused by Mutations in the HvDWARF, HvCPD and HvBRI1 Genes Increase the Tolerance of Barley to the Deacclimation Process
}

\author{
Ewa Pociecha ${ }^{1}$ (D) Anna Janeczko ${ }^{2} \cdot$ Michał Dziurka $^{2} \cdot$ Damian Gruszka $^{3}$
}

Received: 16 December 2019 / Accepted: 19 June 2020 / Published online: 5 July 2020

(c) The Author(s) 2020

\begin{abstract}
Tolerance to deacclimation is an important physiological feature in plants in the face of global warming, which is resulting in incidents of increases in winter temperatures. The aim of the work was to explore how disturbances in the signalling and synthesis of brassinosteroids (BR) influence the deacclimation tolerance of barley. One group of mutants and their reference cultivars (Bowman and Delisa) was cold-acclimated, deacclimated and then tested for frost tolerance at $-12{ }^{\circ} \mathrm{C}$. After cold acclimation, the second group of plants was additionally exposed to frost $\left(-6^{\circ} \mathrm{C}\right)$ and then, deacclimated and tested for frost tolerance at $-12{ }^{\circ} \mathrm{C}$. The deacclimated brassinosteroid mutants were characterised by an increased tolerance to frost, and consequently, had a higher tolerance to deacclimation than their wild-type cultivars. The mechanism of this phenomenon may be partly explained by analysing the hormonal homeostasis in the crowns. For all of the tested plants, a characteristic feature of the response to the deacclimation phase was an increase in the growth-promoting hormones and abscisic acid compared to the cold acclimation phase. The increase was greater in the BR-deficient (BW084) and BR-insensitive (BW312) mutants compared to the Bowman reference cultivar. Mutant 522DK was characterised by a lower accumulation of total cytokinins and gibberellins as well as an enhanced auxin deactivation compared to the Delisa. In the second group, when the plants were exposed to a temperature of $-6^{\circ} \mathrm{C}$ before deacclimation, the hormonal homeostasis was further altered in both the mutants and reference cultivars, but all of the mutants had a higher frost tolerance than the wild types.
\end{abstract}

Keywords Brassinosteroids $\cdot$ Cold acclimation $\cdot$ Deacclimation $\cdot$ Frost tolerance $\cdot$ Phytohormones

\section{Introduction}

Herbaceous plants such as barley, which originate from a temperate geographical zone, usually display a certain basal level of tolerance to frost that is increased after exposure to low temperatures during cold acclimation. During cold

Ewa Pociecha

rrchilmo@cyf-kr.edu.pl

1 Department of Plant Breeding, Physiology and Seed Science, Faculty of Agriculture and Economics, University of Agriculture in Krakow, Podłużna 3, 30-239 Krakow, Poland

2 The Franciszek Górski Institute of Plant Physiology, Polish Academy of Sciences, Niezapominajek 21, 30-239 Krakow, Poland

3 Institute of Biology, Biotechnology and Environmental Protection, Faculty of Natural Sciences, University of Silesia, Jagiellonska 28, 40-032 Katowice, Poland acclimation, the transcriptomes are reprogrammed along with a series of other biochemical, physiological and morphological changes including growth inhibition, which enables plants to increase their tolerance to frost. Ongoing climate changes as well as the predicted increase in temperature in autumn and winter may be decisive for the process of acclimation to the cold (Stocker et al. 2013). The occurrence of periods of warming during winter increases the risk of the deacclimation of plants and may lead to a decrease in their tolerance to frost, which can significantly reduce the yield of crop plants. In contrast to Arabidopsis (Zuther et al. 2015) and annual bluegrass (Hoffman et al. 2014), the rate of deacclimation in cereals is not dependent on the degree of freezing tolerance of cold-acclimated (Rapacz et al. 2017).

In response to warmer temperatures, cold-acclimated plants lose their freezing tolerance and resume growth and development. A transcriptional analysis in Arabidopsis showed the relevance of altered hormonal regulation during deacclimation in response to warm temperatures. The 
upregulation of the genes, which are connected to the regulation of the metabolism of auxins, gibberellins and brassinosteroids, is probably related to the resumption of growth (Pagter et al. 2017). Another factor that leads to deacclimation is the induction of generative development at the level of the hormonal signals that is caused by an increase in temperature. On the other hand, in Arabidopsis, an adaptive strategy to prevent the rapid reversion of the cold acclimation responses is the maintenance of the $\mathrm{H}_{2} \mathrm{O}_{2}$ levels in the plastid antioxidant system during deacclimation (Juszczak et al. 2016).

Brassinosteroids (BR) are steroid hormones that regulate vegetative and reproductive development by promoting cell division and cell elongation (Clouse 2011). A higher content of brassinosteroids accompanied the frost tolerance of winter wheat cultivars, while plant supplementation with 24-epibrassinolide before cold acclimation reduced the number of frost injuries (Janeczko et al. 2019). Brassinosteroids also stimulate the photoprotective mechanisms during prolonged exposure to cold via the temporary suppression of the quantum efficiency of PSII, which is a consequence of energy dissipation in the form of non-photochemical quenching. In Lolium perenne and Secale cereale, the regulation of photosynthetic activity induced by brassinosteroids depends on the temperature and the stage of cold acclimation (Pociecha et al. 2016a, b; Pociecha et al. 2017). Eremina et al. (2016) showed that Arabidopsis thaliana mutants with brassinosteroid signalling deficiencies were hypersensitive to freezing both before and after cold acclimation. Conversely, the activation of brassinosteroid signalling enhanced plant freezing tolerance. According to the same authors, in cold temperatures, brassinosteroids can have an impact on the expression levels of the C-REPEAT/DEHYDRATION-RESPONSIVE ELEMENT BINDING FACTOR (CBF). They provided evidence that the BR-controlled basic helix-loop-helix transcription factor CESTA (CES) can contribute to the constitutive expression of the $\mathrm{CBF}$ transcriptional regulators that control the cold-responsive COR (cold-regulated proteins) gene expression. In the cold, the fast and transient induction of the $\mathrm{CBF}$ transcription factors, which regulate the expression of many of the genes that are associated with a tolerance to low temperatures, is characteristic (Liu et al. 1998).

The reserve carbohydrates that are discharged into the crowns can be used as the source of the energy and metabolites that are necessary for the defence response under frost. Our previous results, which were described in Pociecha et al. (2013), indicated the key role of the crowns for winter tolerance. Crowns are the non-green underground stem parts that contain the shoot apical meristem. Our subsequent studies (Pociecha and Dziurka 2015) showed that in cold-acclimated plants that had been treated with
Trichoderma, the assimilates were targeted to the roots instead of the crowns, which negatively affected their winter tolerance. This proves the strategic role of the crowns in the response to winter stress and that is why the plant crowns will be the main object of the analyses in this work.

Growth regulators, which are called phytohormones, control the fundamental processes in plants such as growth and development and integrate the endogenous and environmental signals. Auxins and cytokinins regulate the cell cycle, gibberellins induce seed germination and stem elongation, while abscisic acid maintains seed dormancy. Antagonistic interactions between auxins and cytokinins in regulating root-shoot differentiation and between gibberellins and abscisic acid during germination are well known. The auxin and BR pathways converge and mutually regulate some developmental processes and promote cell expansion (Davies 2010). The role of hormones, which are essential components of the cell metabolism that is responsible for modulating the plant-environment interaction that enables plants to flexibly adapt to changing environmental conditions is particularly important. Therefore, the concentration of plant hormones is subject to change during both plant development and under the influence of environmental conditions including temperature changes. For example, an increase in the levels of certain cytokinins as a result of vernalisation (cold acclimation) in winter crops, e.g. oilseed rape, is associated with the induction of plant flowering (Tarkowska et al. 2012). In turn, an increase in the level of the abscisic acid stress hormone (abscisic acid) occurs in maize as a defensive response to cold stress (Janowiak et al. 2003). Further, jasmonic acid is an important regulator of the pathogen defence responses and other stress-related pathways (Ahmad et al. 2016). Salicylic acid is also amongst the players that are engaged in the plant-environment interaction including the plant response to temperature stress (Khan et al. 2015). It is worth emphasizing that the role of hormonal management has mainly been studied in relation to high temperature/cold/ frost stress/acclimation. Complex changes in the hormonal homeostasis during deacclimation processes, to the best of our knowledge, remain unexplained although Pagter et al. (2017) predicted the role of plant growth regulators in the process based on a genetic analysis. Describing hormonal alterations during the deacclimation phase in barley plants will then be a crucial part of our studies.

The main aim of the work was to explore how mutations in the HvDWARF, HvCPD and HvBRII genes, which affect the biosynthesis and signalling of brassinosteroids, influence the deacclimation tolerance of barley. We verified the hypothesis that brassinosteroid biosynthesis and signalling disturbances have an effect on the level of other phytohormones in a way that influences frost tolerance after deacclimation. 
Assuming that there are differences between plants with mutations in BR biosynthesis/signalling and their reference cultivars, the aim of the study was to determine the changes in the phytohormone levels that occur during deacclimation and to characterise the interplay between BR and other phytohormones which might be responsible for altering the frost tolerance of deacclimated barley.

\section{Materials and Methods}

\section{Plant Material}

The plant material for this study comprised the semi-dwarf barley Near-Isogenic Lines (NILs) with the reference cultivar Bowman and the semi-dwarf, BR-deficient mutant from the Delisa cultivar. These genotypes were obtained from the collection of the Plant Genetics of Functional Genomics Group, University of Silesia (Poland). The BW084 line (brh13.p), which has a missense mutation in the HvCPD gene, is defective in BR biosynthesis. The BW312 line (ert-ii.79), which has a missense mutation in the HvBRII gene encoding the BR receptor, is a BR-insensitive barley mutant (Dockter et al. 2014). The reference for these NILs is the Bowman cultivar. The 522DK mutant, which was derived from the Delisa cultivar, has a missense mutation in the HvDWARF gene encoding the C6-oxidase, which is involved in BR biosynthesis, and consequently, is impaired in this process (Gruszka et al. 2011, 2016).

The BW084 and 522DK, which are BR-deficient mutants, are characterised by a lower level of BR compared to the reference cultivars, while the signalling mutant BR312 has an increased level of BR (Dockter et al. 2014; Sadura et al. 2019). These differences are maintained in both plants that are cultured at $20^{\circ} \mathrm{C}$ and in cold-acclimated plants (Sadura et al. 2019). The BR deficiency is stronger in BW084 than in 522DK and is connected with disturbances in the BR biosynthetic pathways in the earlier (BW084) and later (522DK) stages of BR biosynthesis, respectively (Sadura et al. 2019).

\section{Experimental Design}

After being sown in pots, the plants were placed in a growth chamber at a temperature of $20{ }^{\circ} \mathrm{C} / 18{ }^{\circ} \mathrm{C}$ (day/ night) with a photoperiod of $10 \mathrm{~h} / 14 \mathrm{~h}$ (day/night) and $300 \mu \mathrm{mol} \mathrm{m}{ }^{-2} \mathrm{~s}^{-1}$ PPFD light (photosynthetic photon flux density). After reaching the three-leaf phase, the plants were cold-acclimated at $5{ }^{\circ} \mathrm{C} / 5{ }^{\circ} \mathrm{C}$ (day/night) with a photoperiod of $8 \mathrm{~h} / 16 \mathrm{~h}$ (day/night) and $250 \mu \mathrm{mol} \mathrm{m}{ }^{-2} \mathrm{~s}^{-1}$ PPFD for three weeks. After cold acclimation, half of the plants from each genotype were deacclimated at $12{ }^{\circ} \mathrm{C} / 10{ }^{\circ} \mathrm{C}$ (day/ night) $8 \mathrm{~h} / 16 \mathrm{~h}$ (day/night) and $250 \mu \mathrm{mol} \mathrm{m}^{-2} \mathrm{~s}^{-1}$ PPFD for ten days and at $18{ }^{\circ} \mathrm{C} / 16^{\circ} \mathrm{C}$ (day/night) $8 \mathrm{~h} / 16 \mathrm{~h}$ (day/ night) and $250 \mu \mathrm{mol} \mathrm{m} \mathrm{m}^{-2} \mathrm{~s}^{-1}$ PPFD for three days. After cold acclimation, the other half of the plants were exposed to frost $\left(-6^{\circ} \mathrm{C}\right)$ for four hours, which is a temperature that did not cause any visible injuries, and then, were deacclimated as above. The temperature $-6{ }^{\circ} \mathrm{C}$ was selected based on our experience and earlier experiment (Sadura et al. 2019). After deacclimation, a freezing test at $-12{ }^{\circ} \mathrm{C}$ was performed for the plants from both groups. The experiment was performed in two independent replications. The samples for the analysis were taken from the crowns - the non-green underground stem parts that contain the shoot apical meristem - before acclimation, after cold acclimation and after deacclimation.

\section{Freezing Tolerance}

The freezing tolerance of the plants after deacclimation was estimated using the modified method of Larsen (1978). The plants in the pots were transferred to a growth chamber at $2 / 2{ }^{\circ} \mathrm{C}$ (day/night) in the dark and, after $2 \mathrm{~h}$, the temperature was successively reduced at a cooling rate of $4^{\circ} \mathrm{C} \mathrm{h}^{-1}$. After reaching the test temperature $\left(-12^{\circ} \mathrm{C}\right)$, the plants were kept there for four hours and then the temperature was increased to $2 / 2{ }^{\circ} \mathrm{C}$ (day/night) for two hours. Next, the pots with the plants were transferred to $\mathrm{a}+12{ }^{\circ} \mathrm{C} / 10{ }^{\circ} \mathrm{C}$ (day/night) with a $10 \mathrm{~h}$ photoperiod and $200 \mu \mathrm{mol} \mathrm{m} \mathrm{m}^{-2} \mathrm{~s}^{-1}$ PPFD. The leaves above the crown were cut off from all of the plants on the day they were transferred to $12{ }^{\circ} \mathrm{C}$. After two weeks, the regrowth was estimated using the visual 9-point scoring system (where 0-dead plants and 9-uninjured wellgrowing plants) as described in Pociecha et al. (2016a, b). Plant regrowth reflected the post-deacclimation freezing tolerance and was estimated based on 30 plants from each genotype per each treatment.

\section{Content of Phytohormones}

The phytohormones were extracted and purified as described by Dziurka et al. (2016). The phytohormones were analysed in three independent replications on a Agilent Infinity 1260 UHPLC apparatus (Agilent, Waldbronn, Germany), attached to a triple quadruple mass spectrometer (6410 Triple Quad LC/MS, Agilent, Santa Clara, CA, USA) and equipped with electrospray ionisation (ESI) as described in Sadura et al. (2019). The following phytohormones were detected auxins: indole-3-acetic acid (IAA), oxindole-3-acetic acid (oxIAA), indole-3-butyric acid (IBA), indole-3-acetic acid methyl ester (IAAmet); cytokinins: trans-zeatin (t-Z), trans-zeatin riboside (t-ZR), dihydrozeatin (DH Z), cis-zeatin (c-Z), cis-zeatin riboside (c-ZR), kinetin, N6-isopentenyladenine (IPA); gibberellins: gibberellin $\mathrm{A}_{1}\left(\mathrm{GA}_{1}\right)$, gibberellic acid $\left(\mathrm{GA}_{3}\right)$, gibberellin $\mathrm{A}_{4}\left(\mathrm{GA}_{4}\right)$, gibberellin $\mathrm{A}_{5}\left(\mathrm{GA}_{5}\right)$, 
gibberellins $\mathrm{A}_{6}\left(\mathrm{GA}_{6}\right)$; abscisic acid (ABA), jasmonic acid (JA) and salicylic acid (SA).

\section{Statistical Analysis of the Results}

The data were analysed using a one-way analysis of variance (ANOVA). The graphs were plotted using the means \pm SD. A post hoc comparison was conducted using Duncan's multiple range test $(p \leq 0.05)$. All of the calculations were carried out using the STATISTICA 10.0 software package (StatSoft, Inc., Tulsa, OK USA).

\section{Results and Discussion}

\section{Frost Tolerance After Deacclimation}

Previous studies that have been conducted on the barley mutants BW312 and BW084 showed that mutations in the $H v B R I 1$ and $H v C P D$ genes significantly reduced frost tolerance (test at $-8{ }^{\circ} \mathrm{C}$ ), which was assessed after cold acclimation, compared to the reference cultivar Bowman (Sadura et al. 2019). In addition, the brassinosteroiddeficient (BW084) mutant was characterised by less capacity to survive temperatures below $0{ }^{\circ} \mathrm{C}$ after cold acclimation than the brassinosteroid-insensitive mutant (BW312). In turn, a mutation in the HvDWARF gene, which is also responsible for a brassinosteroid deficiency, did not affect the survival of mutant plants (522DK) at $-8{ }^{\circ} \mathrm{C}$ compared to the Delisa reference cultivar (Sadura et al. 2019).
The results of the presented studies indicate that the barley plants that are cold-acclimated and then subjected to deacclimation were interestingly characterised by an increased capacity to survive temperatures below $0{ }^{\circ} \mathrm{C}$ (Fig. 1, treatment DA). Moreover, the analysed NILs, especially the mutant with the BR-signalling deficiency (BW312) survived a temperature of $-12{ }^{\circ} \mathrm{C}$ uninjured, while the reference Bowman plants that underwent the same treatment had the lowest tolerance. Mutation at the late stage of BR synthesis (in 522DK) resulted in similar level of regrowth, after freezing test of deacclimated plants, as comparing to Delisa. According to our earlier work, when cold-acclimated plants were subjected to freezing at $-6{ }^{\circ} \mathrm{C}$, both the BR biosynthesis and signalling mutants (BW084 and BW312, respectively) had a similar frost tolerance to the Bowman cultivar (Sadura et al. 2019). In the current work, when plants were pre-treated by mild frost $\left(-6^{\circ} \mathrm{C}\right)$, and then deacclimated, all of the tested mutants unambiguously had a higher tolerance to frost $\left(-12^{\circ} \mathrm{C}\right)$ than their reference cultivars (Fig. 1, treatment FR).

Mutation of the HvDWARF gene at the late stage of BR biosynthesis seems to favour survival when deacclimation is preceded by mild frost. In turn, mutation of the HvBRII and $H v C P D$ genes at the early stage of brassinosteroid biosynthesis increased survival to a greater extent in plants not exposed to mild frost before deacclimation.

\section{General Trends in the Phytohormone Changes}

The phytohormone levels, which were analysed in the crowns showed that after cold acclimation, there was

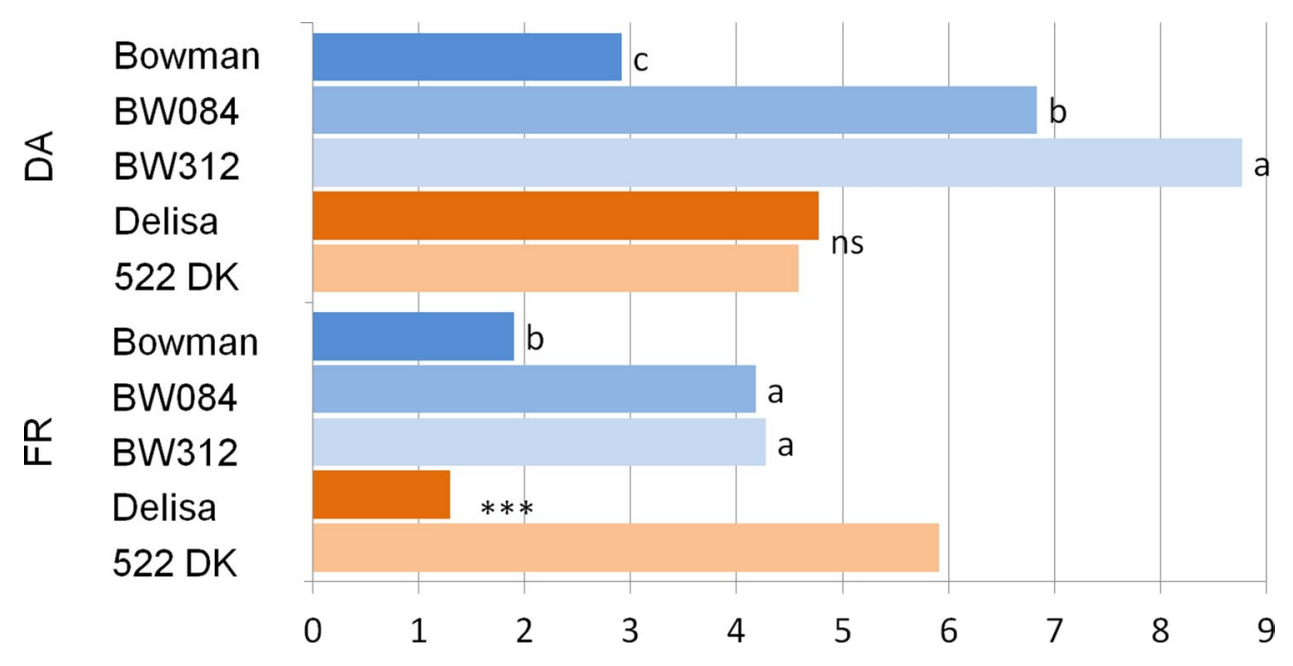

Fig. 1 Frost tolerance based on the regrowth scale of the barley cv. Bowman, BW084 and the BW312 mutant, the cv. Delisa, the 522DK mutant of cold-acclimated and then the deacclimated (DA) and cold-acclimated plants, which had been additionally exposed to frost $\left(-6{ }^{\circ} \mathrm{C}\right)$ and then the deacclimated (FR). Significant differences between the reference cultivar Bowman and its mutants according to Duncan's test, $(P \leq 0.05)$; between the reference cultivar Delisa and the 522DK according to the Student's $t$ test within the treatments are indicated by asterisks $(n=30)$ 
Fig. 2 The total content of cytokinins, gibberellins and auxins in the crowns of the barley cv. Bowman, the BW084 and the 522DK mutant of non-acclimated (NA), cold-acclimated which had been additionally exposed to frost $\left(-6^{\circ} \mathrm{C}\right)$ and then the deacclimated (FR). Significant differences between the cv. Bowman and its mutants according to the Duncan's test, $(P \leq 0.05)$; between the $\mathrm{cv}$. Delisa and the 522DK according to the Student's $t$ test are indicated by asterisks $(n=3)$ BW312 mutant, the cv. Delisa, (CA), deacclimated plants (DA) and cold-acclimated plants,
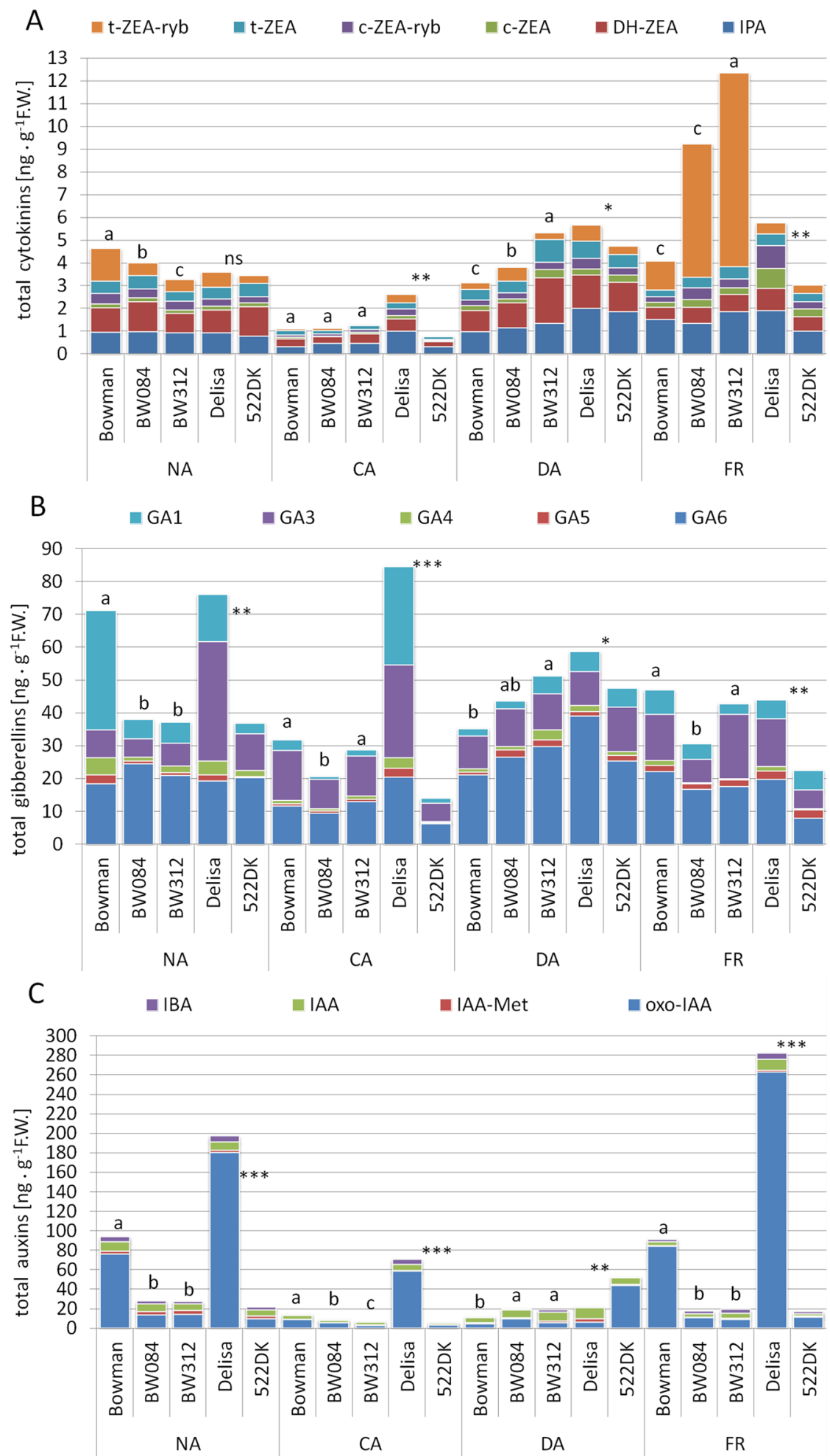

generally a decrease in the level of cytokinins, auxins and gibberellins compared to the non-acclimated plants (Fig. 2). However, after deacclimation, in some cases, the content of all of these groups of hormones increased to a level that was even higher than that prior to the acclimation. Exposure to low temperatures causes the suppression of growth, which is associated with a decrease in gibberellins, cytokinins and auxins and the speed of the response is negatively correlated with the frost tolerance (Vankova et al. 2014; Kosova et al. 2012). All of the non-acclimated mutants were characterised by a significant decrease in the total content of auxins and gibberellins in the crowns (Fig. 2, treatment NA). In 
all of the analysed mutants, not only was there a decrease in the content of the active forms of auxin, but also in that of the form that is considered to be inactive in growth promotion, which is a product of the oxidation of IAA during its decomposition, OxIAA (Reinecke and Bandurski 1983) (Fig. 2, see also Fig. 5). After cold acclimation, there was a relatively high level of all of the groups of hormones, not only auxins and gibberellins but also cytokinins, only in the crowns of the Delisa cultivar. In the remaining plants, there was a visible decrease in the level of the growth-promoting phytohormones after cold acclimation. After deacclimation, differences were observed in the direction of the changes in phytohormone accumulation both between all of the cold-acclimated and all of the deacclimated plants and also between the deacclimated mutants and their reference cultivars (Fig. 2a-c, treatment CA and DA). Generally, the level of total cytokinins and gibberellins increased in all of the deacclimated genotypes compared to those that were coldacclimated. An exception was a decrease in gibberellins in the Delisa. Compared to the Bowman, the level of cytokinins and gibberellins rose in BW084 and BW312, while a mutation in the HvDWARF gene (mutant 522DK vs Delisa) led to a decrease in the levels of these hormones (Fig. 2a and b). In all of the tested mutants, the level of total auxins after deacclimation was lower compared to their reference cultivars (Fig. 2c). Summarising, mutation at an early stage of BR synthesis (in BW084) and mutation in brassinosteroid signalling (in BW312) are accompanied by an increase in the phytohormones (cytokinins and gibberellins) during deacclimation while mutation at the late stage of BR synthesis (in 522DK) results in a decrease in level of these growth-promoting phytohormones. Simultaneously, all of the mutations were accompanied by fewer total auxins in the deacclimated mutant plants, although there were visible differences in the level of specific auxins. The short-term exposure of plants to mild frost prior to deacclimation, significantly increased the cytokinins concentration in the BW084 and BW312 mutants compared to the Bowman (Fig. 2a, treatment FR). This effect was mainly caused by trans-zeatin riboside (t-ZR), which constituted nearly two-thirds of the general pool of the detected cytokinins (Fig. 2a, see also Fig. 3). In turn, mutation at a late stage of BR synthesis was accompanied by a decrease in the content of the pool of cytokinins in 522DK compared to the Delisa cultivar. Interestingly, although in both group of mutants, the effect was similar, it was more pronounced than in the plants that had been deacclimated without prior frost treatment (Fig. 2, treatment DA and FR). As for the auxins, in contrast to the mutants, the reference cultivars Bowman, and especially the Delisa, displayed an extremely high level of the inactive form of auxin oxIAA (Fig. 2c). These genotypes also had a higher level of total gibberellins (Fig. 2b). Here we can only propose a theory that the higher level of brassinosteroids in the reference cultivars might have contributed to the decomposition of the active forms, IAA, in the crowns, but in this case, only in the deacclimated plants that had been exposed to mild frost earlier (treatment FR). A similar phenomenon has also been observed in barley leaves during acclimation to cold (Sadura et al. 2019). Interestingly, the opposite effect was observed for the deacclimated plants (Fig. 5, DA treatment) in which both the BR-deficient mutants had an increased level of oxIAA compared to the respective wild types. The role and distribution (crowns/leaves) of oxIAA and its interplay with BR in the processes of acclimation/deacclimation will require more detailed studies.

Growth suppression at cold temperatures appears to be a necessary condition for the reallocation of the sources of energy for the synthesis of protective compounds. This regulation occurs at both the level of synthesis and the transduction of the signal associated by stimulating cell division and growth. According to Miki et al. (2019), the abiotic stress-responsive proteins and the protein kinases/ phosphatases, which decrease during cold acclimation generally show the opposite behaviour during deacclimation. Moreover, studies by Pagter et al. (2017) showed that the genes that are involved in the hormone metabolism were the only functional group that was overrepresented amongst the upregulated genes at different time points, which indicates the relevance of hormonal regulation during deacclimation. According to the same authors, the upregulation of the genes, which are connected to the regulation of the metabolism of auxins, gibberellins and brassinosteroids, is probably related to the resumption of growth in response to deacclimation, while amongst the genes that are downregulated in cold temperatures, there was an overrepresentation of the auxin-induced and BR-responsive genes. This indicates the significant role of brassinosteroids as one of factors that is important during both the acclimation to cold as well as during deacclimation. Interestingly, however, a higher content of endogenous BR seems to be preferable for a higher frost tolerance after cold acclimation as was also shown in our earlier studies on a few cultivars of winter wheat (Janeczko et al. 2019). BR-insensitivity or a significant deficit of $B R$, which is the result of disturbances in BR biosynthesis during the early stages of the BR biosynthetic pathways, appeared to be beneficial for a better frost tolerance after deacclimation. When the BR level was relatively slightly decreased as a result of disturbances during the last stages of BR biosynthesis (mutant 522DK), frost tolerance after cold acclimation may not be lower as was shown by Sadura et al. (2019). However, deacclimated plants can still better tolerate sudden frost episodes. 

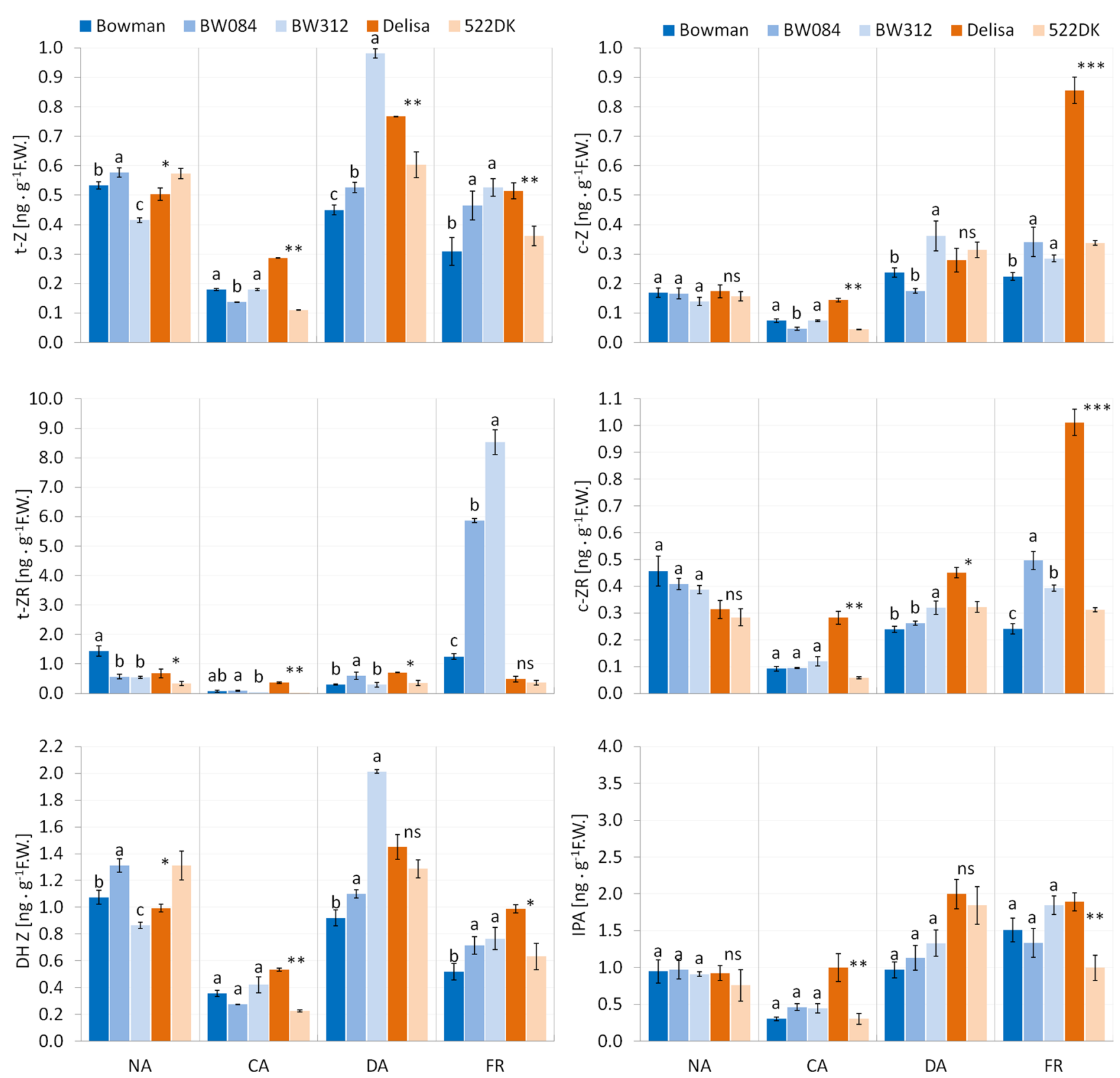

Fig. 3 The cytokinin profile in the crowns of the barley cv. Bowman, the BW084 and BW312 mutant, the cv. Delisa, the 522DK mutant of non-acclimated (NA), cold-acclimated (CA), deacclimated plants (DA) and cold-acclimated plants, which had been additionally exposed to frost $\left(-6^{\circ} \mathrm{C}\right)$ and then deacclimated (FR). Significant dif-

ferences between the cv. Bowman and its mutants according to Duncan's test, $(P \leq 0.05)$; between the cv. Delisa and 522DK according to Student's $t$ test are indicated by asterisks $(n=3)$. Kinetin was detected only in the frozen and deacclimated plants (FR) of BW084, BW312 and the Delisa (inserted graph)

\section{Changes in the Profile of Cytokinins}

The amount of cytokinins decreased significantly after cold acclimation and increased once again after deacclimation (Figs. 2a and 3). The greatest increase in cytokinins occurred in the BW312 and BW084 mutants when deacclimation was preceded by mild frost. The study revealed that in those plants, the trans-isomer of the

zeatin riboside (t-ZR) dominated the cytokinin spectrum (Fig. 3). The t-ZR exhibits a higher cell division-promoting activity compared to the much less active c-ZR (Schäfer et al. 2015). The domination of the t-ZR in the cytokinins profile could be considered to be responsible for the higher growth potential of the plants that were exposed to a mild frost $\left(-6{ }^{\circ} \mathrm{C}\right)$ before deacclimation. Additionally, kinetin was only detected in the frozen and deacclimated plants 
that had mutations in the $H v B R I I$ and $H v C P D$ genes and in the Delisa cultivar (Fig. 3, inserted graph). Pagter and Arora (2013) suggested that at higher temperatures during deacclimation, the requirements of plants for carbon sources increases, and that this is connected with the increased rate of respiration and the resumption of growth. An increase in the t-ZR in the crowns, which are the main meristematic tissues that are responsible for plant regrowth, may be related to this significant element, which is crucial for overwintering. In the Delisa, the relatively low frost tolerance in the plants that had been subjected to mild frost before deacclimation could be the result of the particularly high $\mathrm{c}-\mathrm{Z}$ and $\mathrm{c}-\mathrm{ZR}$ and the potential transition between the vegetative and generative developmental phases. Peak c-ZR was found at the very beginning of the vegetative phase of the reproductive developmental transitions in cold-treated Triticum monococcum (Vankova et al. 2014). Interestingly, because the 522DK mutant was characterised by a lower content of cytokinins than its reference cultivar Delisa after deacclimation, the mechanism of its increased tolerance to frost after deacclimation requires further investigation. Further, it is likely that the opposite directions of change in the total cytokinins and individual cytokinins in the Bowman NILs (BW312 and BW084) and in the 522DK mutant compared to their reference cultivars (particularly in the case of the FR treatment) could be attributed to the background of the cultivar. Because of such a cultivar-dependency, cytokinins should not be considered to be universal players that participate in the mechanisms that are responsible for the higher tolerance to deacclimation in BR-deficient or BR-insensitive barley.

\section{Changes in the Profile of Gibberellins}

All of the non-acclimated mutants had a lower level of total gibberellins compared to their reference cultivars. At the same time, they also had a clear predominance of $\mathrm{GA}_{6}$ over the other gibberellins. Generally, the greatest abundance of $\mathrm{GA}_{6}$ seemed to occur in the deacclimated but not frost pretreated plants (Fig. 4). After deacclimation, an increase in the level of $\mathrm{GA}_{5}$ and $\mathrm{GA}_{6}$ was observed in the BR-deficient (BW084) and BR-insensitive mutants. However, a mutation in the HvDWARF gene in 522DK was accompanied by a decrease in $\mathrm{GA}_{6}$ (Fig. 4). The $\mathrm{GA}_{6}$ content exceeded the combined content of $\mathrm{GA}_{1}, \mathrm{GA}_{3}$ and $\mathrm{GA}_{4}$, which are the active forms of the gibberellins that are responsible for promoting growth and stimulate stem elongation much more effectively than $\mathrm{GA}_{5}$ or $\mathrm{GA}_{6}$. Indeed, the $\mathrm{GA}_{6}$ content increases in grasses when the induction of flowering begins (Hedden and Thomas 2012). In Lolium temulentum, the endogenous $\mathrm{GA}_{5}$ and $\mathrm{GA}_{6}$ that are produced in the leaves in response to long days, which are then transported to the apex, have been suggested to control the early events of floral initiation (King et al. 2003). In barley, gibberellins are required for normal flowering (Boden et al. 2014) and therefore an increase in their accumulation would suggest that they are activated in the signalling pathways that are associated with the induction of generative development (and that this lowers the frost tolerance). Interestingly, for example, after deacclimation (Fig. 4, treatment DA), the most frosttolerant plant was the signalling mutant (BW312) despite the increase in the content of $\mathrm{GA}_{1}, \mathrm{GA}_{4}, \mathrm{GA}_{5}$ and $\mathrm{GA}_{6}$ (Fig. 4). Here, we are probably dealing with another mechanism that is independent on the mechanism of the suppression of the floral induction pathways, connected to an increased frost tolerance. Interestingly, such a mechanism would more probably occur in the mutant 522DK, which had a higher frost tolerance after deacclimation (treatment DA and FR) than the Delisa, which was accompanied by a lower content of the total gibberellins as well as in some of the individual gibberellins such as GA4 or GA6 (Fig. 4). To conclude, similar to cytokinins there is no unequivocal picture of the changes in gibberellins after the deacclimation of barley in all mutants.

\section{Changes in the Profile of Auxin}

A BR deficiency and disturbances in signalling were already decisive with regard to the lower content of total auxin in all of the mutants prior to cold acclimation (Fig. 2c). The effect was similar in the cold-acclimated plants and the deacclimated plants (treatment FR) but not in the plants that had been deacclimated without the frost pre-treatment (DA). As for the individual active auxins, after deacclimation (treatment DA and FR), the content of IAA and IBA in mutants BW084 and BW312 was usually higher than in the Bowman, while in the 522DK, it was lower than in the Delisa. We suspect that this may have been an effect of the genetic background (Bowman, Delisa), which makes it difficult to explain the role of the concentration of active auxins in a BR-dependent higher frost tolerance. The changes in the concentration of the IAA methyl ester (IAAmet, Fig. 5) were quite similar in the deacclimated mutants compared to the reference cultivars. Vankova et al. (2014) reported a decreased IAA level during the early response to cold treatment in the crowns in the spring line DV92 and winter line G3116 with a transient maximum at days 21 and 42, respectively. In our experiment, when all of the treatments were compared, the most abundant metabolite was the non-active product of the IAA decomposition, oxIAA (Fig. 5). Once again, according to Vankova et al. (2014), IAA-aspartate (deactivated IAA) was most abundant in the crowns and was relatively low in leaves. Its level was higher in the winter line than in the spring line. A high accumulation of deactivated 

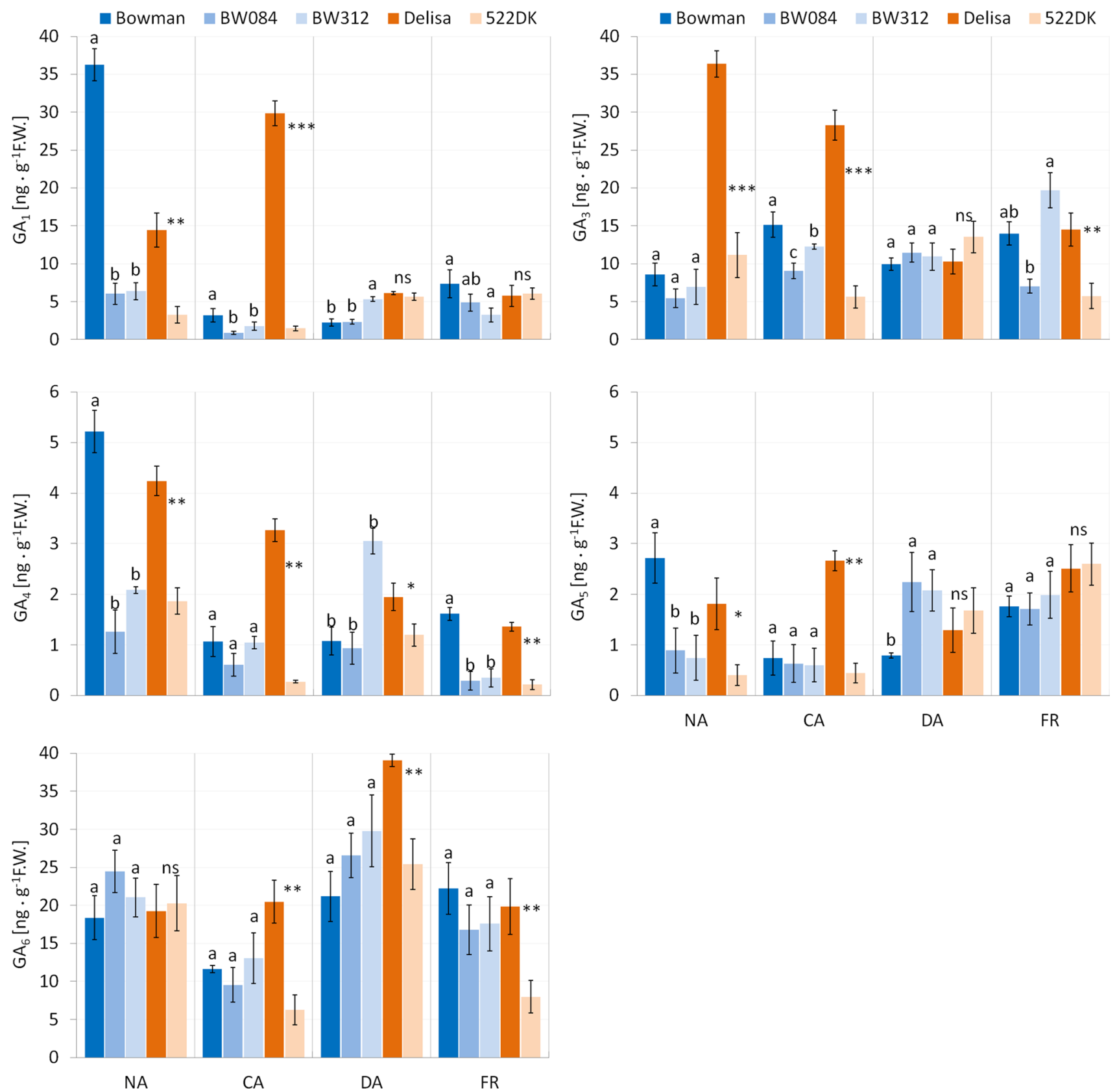

Fig. 4 The gibberellin profile in the crowns of the barley cv. Bowman, the BW084 and BW312 mutant, the cv. Delisa, the 522DK mutant of non-acclimated (NA), cold-acclimated (CA), deacclimated plants (DA) and cold-acclimated plants, which had been additionally

exposed to frost $\left(-6^{\circ} \mathrm{C}\right)$ and then deacclimated (FR). Significant differences between the $\mathrm{cv}$. Bowman and its mutants according to the Duncan's test, $(P \leq 0.05)$; between the cv. Delisa and 522DK according to the Student's $t$ test are indicated by asterisks $(n=3)$

auxins would be justified as a mechanism to limit plant growth and as a step that is required to acquire a tolerance to stress. In our studies, however, after the deacclimation that had been preceded by frost $\left(-6^{\circ} \mathrm{C}\right)$, the oxIAA level was relatively low in the frost-tolerant mutants, but was highly abundant in the reference cultivars, which were characterised by a lower frost tolerance. Moreover, the phenomenon was

opposite when the plants were deacclimated but not frost pre-treated (Fig. 5, treatment DA).

\section{Changes in Specific Stress Hormones}

The opposite changes in the ABA, SA and JA content was demonstrated before the cold acclimation, in which a low level of the ABA concentration coincided with a high level 

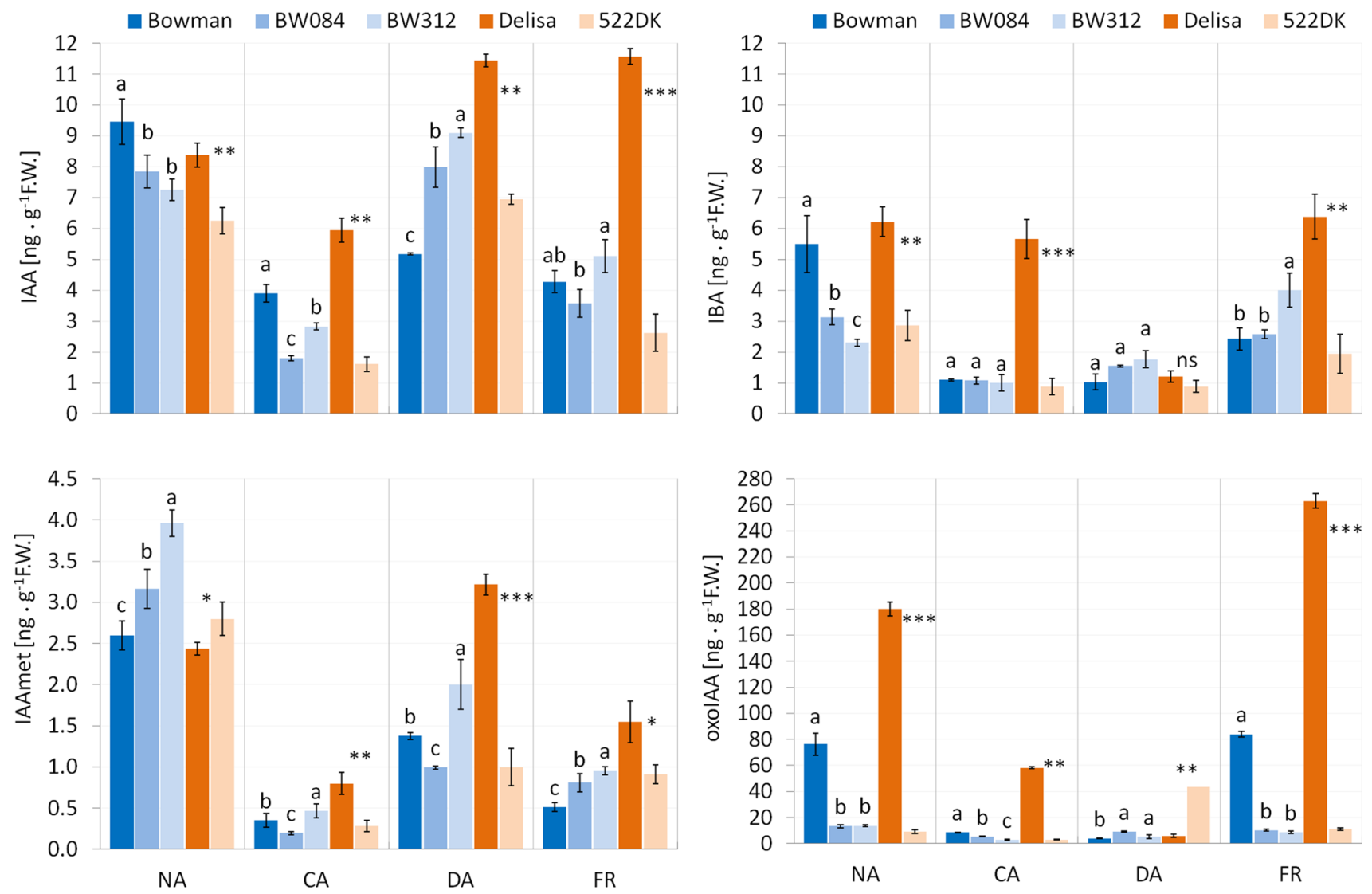

Fig. 5 The auxin profile in the crowns of the barley cv. Bowman, the BW084 and BW312 mutant, the cv. Delisa, the 522DK mutant of the non-acclimated (NA), cold-acclimated (CA), deacclimated plants (DA) and cold-acclimated plants, which had been additionally

exposed to frost $\left(-6^{\circ} \mathrm{C}\right)$ and then deacclimated (FR). Significant differences between the $\mathrm{cv}$. Bowman and its mutants according to the Duncan's test, $(P \leq 0.05)$; between the cv. Delisa and 522DK according to the Student's $t$ test are indicated by asterisks $(n=3)$

of the SA and JA content (Fig. 6). A similar response was also observed during the acclimation to cold phase by Vankova et al. (2014). Antagonistic interactions between ABA and the stress hormones SA and JA were also indicated by the coincidence of the high level of ABA along with the downregulation of SA and JA, which occurred in both deacclimation treatments (Fig. 6). Prior to cold acclimation and after deacclimation, the crowns of all of the mutants contained less JA than their reference cultivars (Fig. 6). Generally, after deacclimation, the level of JA fell dramatically in mutants and in the reference cultivars.

Prior to the cold acclimation, the BW084 and BW312 mutants had a decreased level of SA, while the mutation at the late stage of BR synthesis (522DK) was connected to an increased content of this hormone (Fig. 6). After cold acclimation, the level of SA in the crowns decreased significantly. It was also lower in all of the mutants than in their reference cultivars. After deacclimation, the level of SA was extremely low and did not differ amongst the objects.

Mutation at the early stage of synthesis of the brassinosteroids (in BW084) did not have an effect on the level

of ABA (treatments NA, CA and DA, Fig. 6). Mutation in BR signalling pathways (in BW312) resulted in increased ABA level only after acclimation and after deacclimation without freezing (treatments CA and DA, Fig. 6). Not acclimated 522DK mutant was characterised by an increased in the level of ABA; however, the ABA content decreased under the stress conditions during both cold acclimation and deacclimation. The connection between ABA level and frost tolerance of BR-mutants is not very clear picture. The higher frost tolerance of BW084 and BW312 compared to the Bowman was accompanied by an increased content of ABA after deacclimation (treatment DA, Figs. 1 and 6). Simultaneously, the 522DK was characterised by a slightly lower content of $\mathrm{ABA}$ and a very similar frost tolerance compared to the Delisa. The ABA content in the 522DK mutant was much lower when deacclimation was preceded with frost $\left(-6^{\circ} \mathrm{C}\right)$ (Figs. 1 and 6, treatment FR), but frost tolerance of mutant was higher than in Delisa. The BW084 and BW312 mutants were still characterised by a higher frost tolerance compared to the Bowman, but the ABA content in the mutants (especially BW084) was slightly lower than in 

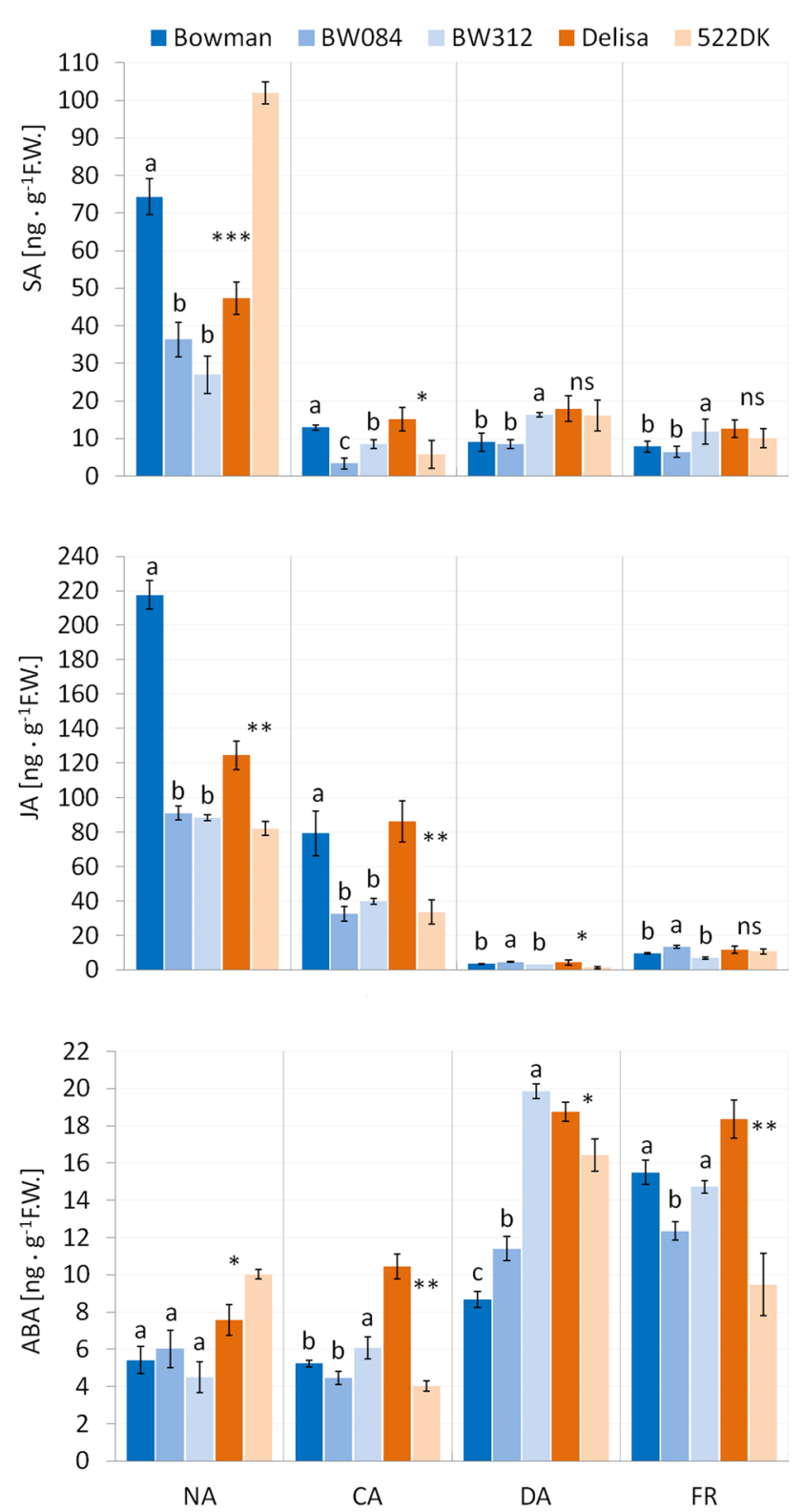

Fig. 6 Salicylic acid (SA), jasmonic acid (JA) and abscisic acid (ABA) content in the crowns of the barley cv. Bowman, the BW084 and BW312 mutant, the cv. Delisa, the 522DK mutant of non-acclimated (NA), cold-acclimated (CA), deacclimated plants (DA) and cold-acclimated plants, which had been additionally exposed to frost $\left(-6{ }^{\circ} \mathrm{C}\right)$ and then deacclimated (FR). Significant differences between the cv. Bowman and its mutants according to the Duncan's test, $(P \leq 0.05)$; between the cv. Delisa and 522DK according to the Student's $t$ test are indicated by asterisks $(n=3)$

the Bowman. As for the 522DK and the Delisa, the higher frost tolerance of the 522DK compared to the Delisa was accompanied by a lower concentration of ABA in the crowns of this mutant.

\section{Concluding Remarks}

Tolerance to deacclimation is important in the face of global warming, which results in temperature instabilities during vegetation periods. Our work provides an insight into the phytohormonal homeostasis in the reaction of barley to changing temperature conditions during the processes of cold acclimation and, especially deacclimation. Further, the exposure of plants to mild frost prior to deacclimation (at a temperature that does not cause visible injuries) had a different effect on the dynamics of the hormonal changes. The most important finding in our work is the fact that the barley mutants that had a lower content of BR or those with BR-insensitivity had a higher tolerance to frost after the deacclimation process (a higher tolerance to deacclimation). Importantly, this fact was independent of the genetic background (Bowman, Delisa) from which the mutants had been derived. Variations in changes in the concentrations of the other phytohormones are often cultivar/genotypedependent and may only be a partial explanation for the altered tolerance of the BR mutants to deacclimation and therefore other mechanisms for this tolerance require further studies. This drew us to conclude that brassinosteroids seem to be one of the more important factors in both during acclimation to cold and, especially during deacclimation. Variations in the hormonal level between the cold acclimated and deacclimated plants and also the altered frost tolerance of the cold acclimated (Sadura et al. 2019) and deacclimated BR-mutants from the Bowman NILs confirms that cold acclimation and deacclimation take independent metabolic pathways.

Acknowledgements The study was financed by the Polish Ministry of Science and Higher Education grant to the Faculty of Agriculture and Economics, University of Agriculture in Krakow, No. DS3113. The work was also supported from project of the National Science Centre (2016-2018) No. 2015/17/B/NZ9/01695 (Poland).

\section{Compliance with Ethical Standards}

Conflict of interest On behalf of all of the authors, the corresponding author states that there are no conflicts of interest.

Open Access This article is licensed under a Creative Commons Attribution 4.0 International License, which permits use, sharing, adaptation, distribution and reproduction in any medium or format, as long as you give appropriate credit to the original author(s) and the source, provide a link to the Creative Commons licence, and indicate if changes were made. The images or other third party material in this article are included in the article's Creative Commons licence, unless indicated otherwise in a credit line to the material. If material is not included in the article's Creative Commons licence and your intended use is not permitted by statutory regulation or exceeds the permitted use, you will need to obtain permission directly from the copyright holder. To view a copy of this licence, visit http://creativecommons .org/licenses/by/4.0/. 


\section{References}

Ahmad P, Rasool S, Gul A, Sheikh SA, Akram NA, Ashraf M, Kazi AM, Gucel S (2016) Jasmonates: multifunctional roles in stress tolerance. Front Plant Sci 7:813

Boden SA, Weiss D, Ross JJ, Davies NW, Trevaskis B, Chandler PM, Swain SM (2014) Early flowering3 regulates flowering in spring barley by mediating gibberellin production and flowering locus $\mathrm{T}$ expression. Plant Cell 26:1557-1569

Clouse SD (2011) Brassinosteroids Arabidopsis Book 9:e0151

Dockter C, Gruszka D, Braumann I, Druka A, Druka I, Franckowiak J, Gough SP, Janeczko A, Kurowska M, Lundqvist J, Lundqvist U, Marzec M, Matyszczak I, Müller AH, Okleštková J, Schulz B, Zakhrabekova S, Hansson M (2014) Induced variations in brassinosteroid genes define barley height and sturdiness, and expand the "Green Revolution" genetic toolkit. Plant Physiol 166:1912-1927

Davies PJ (2010) The plant hormones: their nature, occurrence, and functions. In: Davies PJ (ed) Plant hormones. Springer, Dordrecht

Dziurka M, Janeczko A, Juhász C, Gullner G, Oklestkova J, Novak O, Saja D, Skoczowski A, Tobias I, Barna B (2016) Local and systemic hormonal responses in pepper leaves during compatible and incompatible pepper-tobamovirus interactions. Plant Physiol Biochem 109:355-364

Eremina M, Unterholzner SJ, Rathnayake AI, Castellanos M, Khan M, Kugler KG, May ST, Rozhon MKFX (2016) Brassinosteroids participate in the control of basal and acquired freezing tolerance of plants. Proc Natl Acad Sci USA 113:5982-5991

Gray WM (2004) Hormonal regulation of plant growth and development. Plos Biol 9:1270-1273

Gruszka D, Gorniak M, Glodowska E, Wierus E, Oklestkova J, Janeczko A, Maluszynski M, Szarejko I (2016) A reverse-genetics mutational analysis of the barley $H v D W A R F$ gene results in identification of a series of alleles and mutants with short stature of various degree and disturbance in BR biosynthesis allowing a new insight into the process. Int J Mol Sci 17:600

Gruszka D, Szarejko I, Maluszynski M (2011) Identification of barley DWARF gene involved in brassinosteroid synthesis. Plant Growth Regul 65:343-358

Hedden P, Thomas SG (2012) Gibberellin biosynthesis and its regulation. Biochem J 444:11-25

Hoffman L, DaCosta M, Bertrand A, Castonguay Y, Ebdon JS (2014) Comparative assessment of metabolic responses to cold acclimation and deacclimation in annual bluegrass and creeping bentgrass. Environ End Exp Bot 106:197-206

Janeczko A, Pociecha E, Dziurka M, Jurczyk B, Libik-Konieczny M, Oklestkova J, Novák O, Pilarska M, Filek M, Rudolphi-Skórska E, Sadura I, Siwek A (2019) Changes in content of steroid regulators during cold hardening of winter wheat: steroid physiological/ biochemical activity and impact on frost tolerance. Plant Physiol Biochem 139:215-228

Janowiak F, Luck E, Dörffling K (2003) Chilling tolerance of maize seedlings in the field during cold periods in spring is related to chilling-induced abscisic acid. J Agron Crop Sci 189:156-161

Juszczak I, Cvetkovic J, Zuther E, Hincha DK, Baier M (2016) Natural variation of cold deacclimation correlates with variation of cold-acclimation of the plastid antioxidant system in Arabidopsis thaliana accessions. Front Plant Sci 7:305

King RW, Evans LT, Mander LM, Moritz T, Pharis RP, Twitchin B (2003) Synthesis of gibberellin GA6 and examination of its role in flowering of Lolium temulentum. Phytochemistry 62:77-82

Khan MI, Fatma M, Per TS, Anjum NA, Khan NA (2015) Salicylic acid-induced abiotic stress tolerance and underlying mechanisms in plants. Front Plant Sci 6:462
Kosová K, Prásil IT, Vítámvás P, Dobrev P, Motyka V, Floková K, Novák O, Turecková V, Rolcik J, Pesek B, Trávnicková A, Gaudinová A, Galiba G, Janda T, Vlasáková E, Prásilová P, Vanková $\mathrm{R}$ (2012) Complex phytohormone responses during the cold acclimation of two wheat cultivars differing in cold tolerance, winter Samanta and spring Sandra. J Plant Physiol 169:567-576

Larsen A (1978) Freezing tolerance in grasses. Methods for testing in controlled environments. Department of Farm Crops Report no. 195. As, Norway: Sci. Rep. Agr. University Norway.

Li X, Cai J, Liu F, Zhou Q, Dai T, Cao W, Jiang D (2015) Wheat plants exposed to winter warming are more susceptible to low temperature stress in the spring. Plant Growth Regul 77:11-19

Liu Q, Kasuga M, Sakuma Y, Abe H, Miura S, Yamaguchi-Shinozaki K, Shinozaki K (1998) Two transcription factors, DREB1 and DREB2, with an EREBP/AP2 DNA binding domain separate two cellular signal transduction pathways in drought- and low-temperature responsive gene expression, respectively in Arabidopsis. Plant Cell 10:1391-1406

Law MY, Charles SA, Miki Y, Takahashi D, Kawamura Y, Uemura M (2019) Temporal proteomics of Arabidopsis plasma membrane during cold- and de-acclimation. J Proteom 197:71-81

Pagter M, Alpers J, Erban A, Kopka J, Zuther E, Hincha DK (2017) Rapid transcriptional and metabolic regulation of the deacclimation process in cold acclimated Arabidopsis thaliana. BMC Genom 18:731

Pagter M, Arora R (2013) Winter survival and deacclimation of perennials under warming climate: physiological perspectives. Physiol Plant 147:75-87

Pociecha E, Dziurka M, Oklestkova J, Janeczko A (2016a) Brassinosteroids increase winter survival of winter rye (Secale cereale L.) by affecting photosynthetic capacity and carbohydrate metabolism during cold acclimation. Plant Growth Regul 80:127-213

Pociecha E, Rapacz M, Dziurka M, Kolasińska I (2016b) Mechanisms involved in the regulation of photosynthetic efficiency and carbohydrate partitioning in response to low- and high-temperature flooding triggered in winter rye (Secale cereale) lines with distinct pink snow mold resistances. Plant Physiol Biochem 104:45-53

Pociecha E, Dziurka M, Waligórski P, Krępski K, Janeczko A (2017) 24-Epibrassinolide pre-treatment modifies cold-induced photosynthetic acclimation mechanisms and phytohormone response of perennial ryegrass in cultivar-dependent manner. J Plant Growth Regul 36:618-628

Pociecha E, Dziurka M (2015) Trichoderma stimulates photosynthesis during cold acclimation but decreases soluble carbohydrates content and pink snow mould (M. nivale) resistance of winter rye. Environ End Exp Bot 109:193-200

Pociecha E, Płażek A, Janowiak F, Dubert F, Kolasińska I, Irla M (2013) Factors contributing to enhanced pink snow mould resistance of winter rye (Secale cereale L.): pivotal role of crowns. Physiol Mol Plant Pathol 81:54-63

Rapacz M, Jurczyk B, Sasal M (2017) Deacclimation may be crucial for winter survival of cereals under warming climate. Plant Sci 256:5-15

Reinecke DM, Bandurski RS (1983) Oxindole-3-acetic acid, an indole3-acetic acid catabolite in Zea mays. Plant Physiol 71:211-213

Sadura I, Pociecha E, Dziurka M, Oklestkova J, Novak O, Gruszka D, Janeczko A (2019) Mutations in the HvDWARF, HvCPD and HvBRI1 genes-involved in brassinosteroid biosynthesis/signalling: altered photosynthetic efficiency, hormonal homeostasis and tolerance to high/low temperatures in barley. J Plant Growth Regul 38:1062-1081

Stocker TF, et al. (eds) (2013) Climate change 2013: the physical science basis. Contribution of working group I to the fifth assessment report of the intergovernmental panel on climate change. Cambridge University Press, Cambridge 
Schäfer M, Brütting C, Meza-Canales ID, Großkinsky DK, Vankova R, Baldwin IT, Meldau S (2015) The role of cis-zeatin-type cytokinins in plant growth regulation and mediating responses to environmental interactions. J Exp Bot 66:4873-4884

Tarkowska D, Filek M, Biesaga-Kościelniak J, Marcińska I, Macháčková I, Krekule J, Strnad M (2012) Cytokinins in shoot apices of Brassica napus plants during vernalization. Plant Sci 187:105-112

Vanková R, Kosová K, Dobrev P, Vítámvás P, Trávnicková A, Cvikrova M, Pesek B, Gaudinová A, Musilova J, Prerostova S, Galiba G, Prásil IT (2014) Dynamics of cold acclimation and complex phytohormone responses in Triticum monococcum lines G3116 and DV92 differing in vernalization and frost tolerance level. Environ Exp Bot 101:12-25
Zuther E, Juszczak I, Lee YP, Baier M, Hincha DK (2015) Timedependent deacclimation after cold acclimation in Arabidopsis thaliana accessions. Sci Rep 5:12199

Publisher's Note Springer Nature remains neutral with regard to jurisdictional claims in published maps and institutional affiliations. 